\title{
ANALISIS KOORDINASI SETTING RELE JARAK PADA GI 150 KV KUDUS-JEKULO-PATI SECARA DUA ARAH
}

\author{
Khoiruddin Tansa Nugraha*), Susatyo Handoko, dan Agung Nugroho \\ Departemen Teknik Elektro, Universitas Diponegoro, Semarang \\ Jl. Prof. Sudharto, SH, Kampus UNDIP Tembalang, Semarang 50275, Indonesia \\ ${ }^{*}$ E-mail: ktansa030995@gmail.com
}

\begin{abstract}
Abstrak
Kebutuhan listrik saat ini semakin berkembang pesat dengan seiringnya kemajuan teknologi yang semakin pesat. Kebutuhan listrik ini merupakan kebutuhan yang sangat penting dan juga mendesak. Sehingga diperlukan suatu sistem proteksi agar kinerja dari saluran transmisi dapat bekerja secara kontinyu. Pada saluran transmisi, salah satu proteksi yang digunakan adalah rele jarak. Penelitian penelitian ini bertujuan untuk melakukan analisis koordinasi dan kinerja setting rele jarak Kudus arah Pati secara 2 arah. Setting rele yang didapatkan dari PT. PLN disimulasikan menggunakan software DIgSILENT 14.1 untuk melihat nilai jangkauannya. Standar yang digunakan adalah standar IEEE std C37.113.2015 dan Network Protection \& Automation Guide dari ALSTOM. Terdapat 2 skenario gangguan hubung singkat pada sistem. Skenario pertama disimulasikan dengan jarak 98,28\% dan skenario kedua sebesar 24,11\%. Hasil simulasi menunjukkan bahwa pada kondisi eksisting terdapat rele jarak yang nilai jangkauannya belum sesuai dengan standar. Setelah dilakukan perhitungan ulang (resetting), nilai jangkauan semua rele jarak sudah sesuai dengan standar.
\end{abstract}

Kata kunci: proteksi saluran transmisi, rele jarak, digsilent

\begin{abstract}
Electricity needs of today's growing rapidly with the rapid technological advances. This power requirement is an important necessity and urgency. So we need a protection system for the performance of the transmission line can work continuously. One of the protection used in transmission line is the distance relay. This research is to analyze the performance setting distance relay coordination and direction of the distance relay between Kudus to Pati in 2 directions. Setting relay obtained from PT. PLN and simulated software using DIgSILENT 14.1 to see the value range. The standard used is IEEE std C37.113.2015 and Network Protection \& Automation Guide from ALSTOM. There are 2 scenarios short circuit in the system. The first scenario was simulated with a distance of $98.28 \%$ and $24.11 \%$ for the second scenario. The simulation results show that in existing condition, the distance relay is not in accordance to the standard. After re-calculation (resetting), all reach is in accordance with the standard.
\end{abstract}

Keywords: protection of transmission line, the distance relay, digsilent

\section{Pendahuluan}

Penggunaan listrik sekarang bukan hanya untuk penggunaan rumah tangga saja namun sudah meluas hingga ke industri - industri besar. Sistem tenaga listrik sendiri mempunyai 3 komponen utama yang interkoneksi yaitu sistem pembangkitan, sistem penyaluran, dan beban [1]. Sistem penyaluran merupakan salah satu komponen penting dalam suatu sistem tenaga listrik. Hal ini mengakibatkan saluran transimisi membutuhkan peralatan proteksi guna mengatasi gangguan yang terjadi agar saluran transmisi masih dapat menjalankan fungsinya dengan baik.

Salah satu sistem proteksi pada saluran transmisi adalah rele jarak. Rele jarak bekerja atas dasar perbandingan tegangan (V) dan arus (I) yang terukur pada lokasi rele dimana rele tersebut ditempatkan pada saat terjadinya gangguan [1]. Simulasi koordinasi dan kinerja antara rele jarak satu dengan rele jarak lainnya diperlukan untuk melihat kinerja dari setiap rele yang ada pada gardu induk.

Penelitian yang telah dilakukan sebelumnya adalah perhitungan dan analisis kinerja rele jarak pada subsistem $150 \mathrm{kV}$ secara manual [2] [3]. Penelitian yang lain [4] [5] [6], menyimpulkan bahwa koordinasi dan setting dari rele jarak dapat dicek dan dianalisis oleh Software DIgSILENT PowerFactory. Software DIgSILENT PowerFactory dapat melakukan simulasi koordinasi rele antar jaringan yang direpresentasikan ke dalam Time Distance Coordination dan melakukan simulasi kinerja antara rele satu dengan rele yang lainnya yang direpresentasikan ke dalam $\mathrm{R}-\mathrm{X}$ diagram untuk berbagai macam gangguan [4] [5] [6]. 
Pada penelitian ini telah dilakukan analisa setting dan koordinasi rele jarak pada saluran Kudus-Jekulo-Pati secara 2 arah dengan menggunakan Software DIgSILENT PowerFactory 14.1. Data eksisting dari PT. PLN yang belum sesuai dengan standar akan dilakukan perhitungan ulang (resetting) dan dilakukan analisa kembali setelah resetting.

\section{Metode}

\subsection{Langkah Penelitian}

Penelitian ini dibuat dan dilaksanakan dalam beberapa tahap - tahapan penelitian yang ditampilkan pada Gambar 1 .

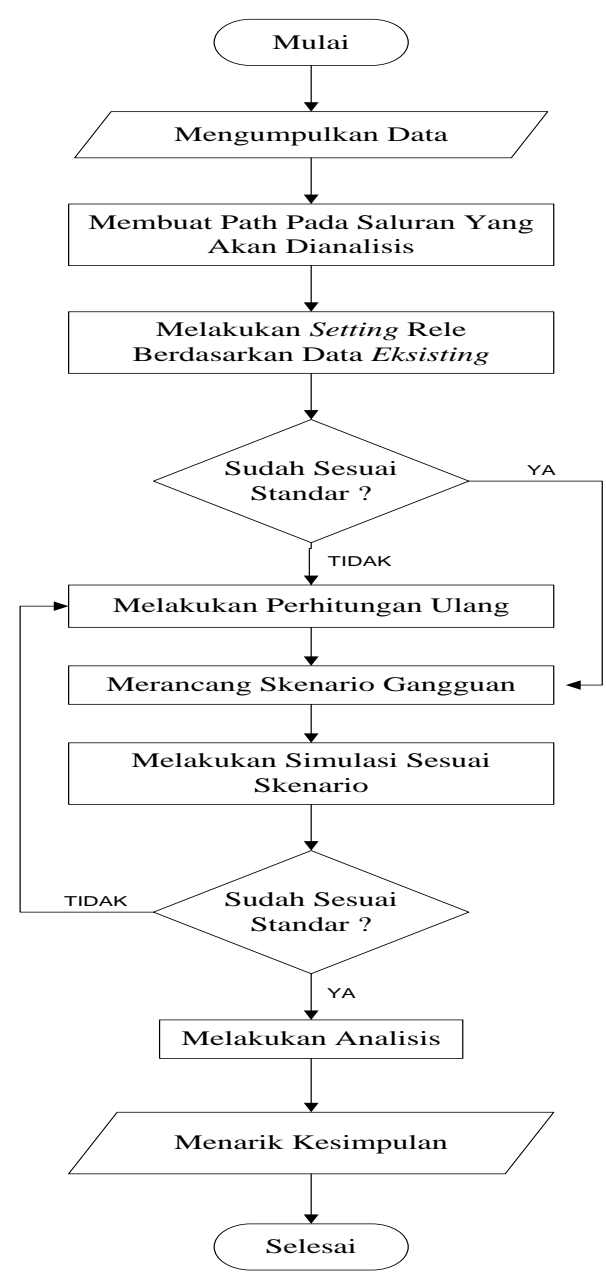

Gambar 1. Flowchart Penelitian

\subsection{Data Penelitian}

Data penelitian diperoleh dari PT. PLN (Persero). Simulasi dilakukan dengan memasukkan data individual rele ke dalam single line software DIgSILENT 14.1 Gambaran dari single line yang dianalisis ditampilkan pada gambar 2. Hasil dari simulasi dengan kondisi eksisting ditampilkan pada Tabel 1.

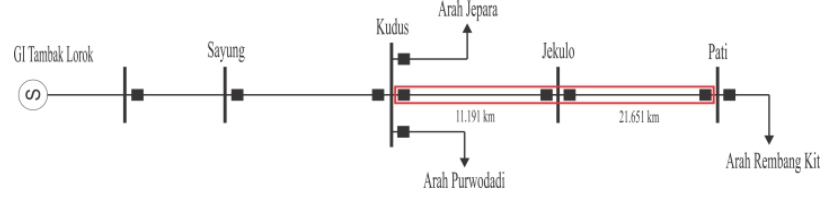

Gambar 2. Single Line yang Dianalisis

Tabel 1. Hasil Nilai Jangkauan Kondisi Eksisting

\begin{tabular}{|c|c|c|c|}
\hline Subsistem & Zona & $\begin{array}{c}\mathrm{Z} \text { sekunder } \\
(\text { ohm })\end{array}$ & $\begin{array}{c}\text { \% Nilai } \\
\text { Jangkauan }\end{array}$ \\
\hline \multirow{3}{*}{ Kudus 1 - Jekulo 1} & Zona 1 & 5,10 & 80,80 \\
\hline & Zona 2 & 12,90 & 204,38 \\
\hline & Zona 3 & 28,48 & 451,22 \\
\hline \multirow{3}{*}{ Kudus 2 - Jekulo 2} & Zona 1 & 5,10 & 80,80 \\
\hline & Zona 2 & 12,86 & 203,75 \\
\hline & Zona 3 & 28,48 & 451,22 \\
\hline \multirow{3}{*}{ Jekulo 1 - Pati 1} & Zona 1 & 9,83 & 80,50 \\
\hline & Zona 2 & 29,95 & 245,27 \\
\hline & Zona 3 & 51,13 & 418,72 \\
\hline \multirow{3}{*}{ Jekulo 2 - Pati 2} & Zona 1 & 9,83 & 80,50 \\
\hline & Zona 2 & 29,25 & 239,53 \\
\hline & Zona 3 & 51,13 & 418,72 \\
\hline \multirow{3}{*}{ Pati 1 - Jekulo 1} & Zona 1 & 9,83 & 80,50 \\
\hline & Zona 2 & 17,74 & 145,28 \\
\hline & Zona 3 & 22,42 & 183,60 \\
\hline \multirow{3}{*}{ Pati 2 - Jekulo 2} & Zona 1 & 9,83 & 80,50 \\
\hline & Zona 2 & 14,78 & 121,04 \\
\hline & Zona 3 & 22,42 & 183,60 \\
\hline \multirow{3}{*}{ Jekulo 1 - Kudus 1} & Zona 1 & 5,47 & 86,66 \\
\hline & Zona 2 & 12,4 & 196,46 \\
\hline & Zona 3 & 39,19 & 620,91 \\
\hline \multirow{3}{*}{ Jekulo 2 - Kudus 2} & Zona 1 & 5,47 & 86,66 \\
\hline & Zona 2 & 12,4 & 196,46 \\
\hline & Zona 3 & 39,19 & 620,91 \\
\hline
\end{tabular}

Hasil dari simulasi data eksisting dibandingkan dengan standar Network Protection \& Automation Guide dari ALSTOM. Hasil perbandingan ditampilkan pada Tabel 2.

Tabel 2. Perbandingan Eksisting dengan Standar

\begin{tabular}{cccc}
\hline Rele & Zona & Standar & $\begin{array}{c}\text { \% Nilai } \\
\text { Jangkauan }\end{array}$ \\
\hline \multirow{2}{*}{ Kudus 1 - Jekulo 1 } & Zona 1 & $80 \mathrm{~s} / \mathrm{d} 90$ & 80.80 \\
& Zona 2 & $120 \mathrm{~s} / \mathrm{d} \mathrm{196.734}$ & 204.38 \\
& Zona 3 & 352.162 & 451.22 \\
Kudus 2 - Jekulo 2 & Zona 1 & $80 \mathrm{~s} / \mathrm{d} 90$ & 80.80 \\
& Zona 2 & $120 \mathrm{~s} / \mathrm{d} \mathrm{196.734}$ & 203.75 \\
& Zona 3 & 352.162 & 451.22 \\
Jekulo 1 - Pati 1 & Zona 1 & $80 \mathrm{~s} / \mathrm{d} 90$ & 80.50 \\
& Zona 2 & $120 \mathrm{~s} / \mathrm{d} \mathrm{223.096}$ & 245.27 \\
& Zona 3 & 415.43 & 418.72 \\
Jekulo 2 - Pati 2 & Zona 1 & $80 \mathrm{~s} / \mathrm{d} 90$ & 80.50 \\
& Zona 2 & $120 \mathrm{~s} / \mathrm{d} \mathrm{223.096}$ & 239.53 \\
& Zona 3 & 415.43 & 418.72 \\
Pati 1 - Jekulo 1 & Zona 1 & $80 \mathrm{~s} / \mathrm{d} 90$ & 80.50 \\
& Zona 2 & $120 \mathrm{~s} / \mathrm{d} \mathrm{125.844}$ & 145.28 \\
& Zona 3 & 182.026 & 183.60 \\
Pati 2 - Jekulo 2 & Zona 1 & $80 \mathrm{~s} / \mathrm{d} 90$ & 80.50 \\
& Zona 2 & $120 \mathrm{~s} / \mathrm{d} \mathrm{125.844}$ & 121.04 \\
& Zona 3 & 182.026 & 183.60 \\
Jekulo 1 - Kudus 1 & Zona 1 & $80 \mathrm{~s} / \mathrm{d} 90$ & 86.66 \\
& Zona 2 & $120 \mathrm{~s} / \mathrm{d} \mathrm{189.665}$ & 196.46 \\
& Zona 3 & 396.08 & 620.91 \\
Jekulo 2 - Kudus 2 & Zona 1 & $80 \mathrm{~s} / \mathrm{d} 90$ & 86.66 \\
& Zona 2 & $120 \mathrm{~s} / \mathrm{d} 189.665$ & 196.46 \\
& Zona 3 & 396.08 & 620.91 \\
\hline
\end{tabular}


Pada Tabel 2 dapat dilihat bahwa hasil simulasi dengan menggunakan data eksisting menunjukkan bahwa terdapat beberapa rele jarak yang belum sesuai dengan standar yang ada. Untuk itu diperlukan resetting dengan menghitung ulang impedansi menggunakan persamaan berikut [7] [8].

1. Perhitungan Impedansi Primer

$Z_{1}=0,85 \times Z L_{11}$

$Z_{2 \min }=1,2 \times Z L_{11}$

$Z_{2 \text { mak }}=Z L_{11}+0,5 Z L_{21}$

$Z_{3}=1,2\left(Z L_{11}+Z L_{31}\right)$

\section{Dimana}

$\mathrm{Z}_{1} \quad=$ setting zona 1 rele jarak

$\mathrm{Z}_{2 \text { min }} \quad=$ setting zona 2 minimum rele jarak

$\mathrm{Z}_{2 \mathrm{mak}}=$ setting zona 2 maksimum rele jarak

$\mathrm{Z}_{3} \quad=$ setting zona 3 rele jarak

$\mathrm{ZL}_{11} \quad$ = impedansi saluran yang diproteksi

$\mathrm{ZL}_{21} \quad=$ impedansi saluran terpendek

$\mathrm{ZL}_{31} \quad=$ impedansi saluran terpanjang

2. Perhitungan Impedansi Sekunder

$Z s=Z p \frac{C T p \times V T s}{C T s \times V T p}$

Dimana

$\mathrm{Z}_{\mathrm{S}} \quad$ = impedansi sekunder

$\mathrm{Z}_{\mathrm{P}} \quad=$ impedansi primer

$\mathrm{CT}_{\mathrm{P}}=$ current transformer primer

$\mathrm{CT}_{\mathrm{S}}=$ current transformer sekunder

$\mathrm{VT}_{\mathrm{P}}=$ voltage transformer primer

$\mathrm{VT}_{\mathrm{S}}=$ voltage transformer sekunder

3. Contoh perhitungan

$\mathrm{L}_{1}=11,191 \mathrm{~km}$

$\mathrm{RL}_{11}=0,036 \Omega / \mathrm{km}$

$\mathrm{ZL}_{11}=\left(\mathrm{RL}_{11}+\mathrm{j} \mathrm{XL}_{11}\right) \cdot \mathrm{L}_{1}$

$\Theta p h 1=\arg \left(\mathrm{ZL}_{11}\right) \mathrm{k}^{-1}$

$\Theta$ ph1 $=82,725 \mathrm{deg}$

$\mathrm{L}_{2}=21,651 \mathrm{~km}$

$\mathrm{RL}_{21}=0,036 \Omega / \mathrm{km}$

$\mathrm{ZL}_{21}=\left(\mathrm{RL}_{21}+\mathrm{j} X \mathrm{~L}_{21}\right) \cdot \mathrm{L}_{2}$

$\Theta \mathrm{ph} 2=\arg \left(\mathrm{ZL}_{21}\right) \mathrm{k}^{-1}$

$\Theta$ ph2 $=82,725 \mathrm{deg}$

$$
\mathrm{XL}_{11}=0,282 \Omega / \mathrm{km}
$$$$
\left|\mathrm{ZL}_{11}\right|=3,181 \Omega
$$

$\mathrm{L}_{3}=21,651 \mathrm{~km}$

$\mathrm{RL}_{31}=0,036 \Omega / \mathrm{km}$

$\mathrm{ZL}_{31}=\left(\mathrm{RL}_{21}+\mathrm{j} \mathrm{XL}_{21}\right) \cdot \mathrm{L}_{2}$

$\Theta p h 2=\arg \left(\mathrm{ZL}_{31}\right) \mathrm{k}^{-1}$

$\Theta p h 2=82,725 \mathrm{deg}$

$\mathrm{XL}_{21}=0,282 \Omega / \mathrm{km}$

$\left|\mathrm{ZL}_{21}\right|=6,155 \Omega$

$\mathrm{XL}_{31}=0,282 \Omega / \mathrm{km}$

$\left|\mathrm{ZL}_{31}\right|=6,155 \Omega$

Zone 1

$\mathrm{Z}_{1 \mathrm{P}}=0,85 \mathrm{ZL}_{11}$

$\left|\mathrm{Z}_{1 \mathrm{P}}\right|=2,704 \Omega$
$\mathrm{Z}_{1 \mathrm{~S}}=\mathrm{Z}_{1 \mathrm{P}} \frac{C T p \times V T s}{C T s \times V T p}$

$\mathrm{Z}_{1 \mathrm{~S}}=3,181 \frac{3000 \times 100}{1 \times 150000}$

$\left|\mathrm{Z}_{1 \mathrm{~S}}\right|=5,409 \Omega$

Zone 2

$\mathrm{Z}_{2 \min }=1,2 \mathrm{ZL}_{11}$

$\mathrm{Z}_{2 \mathrm{mak}}=\mathrm{ZL}_{11}+\left(0,5 \mathrm{ZL}_{21}\right)$

$\mathrm{Z}_{2 \mathrm{P}}=\mathrm{Z}_{\mathrm{mak}}$

$\mathrm{Z}_{2 \mathrm{~S}}=\mathrm{Z}_{2 \mathrm{P}} \frac{C T p \times V T s}{C T s \times V T p}$

$\mathrm{Z}_{1 \mathrm{~S}}=6,259 \frac{3000 \times 100}{1 \times 150000}$

$\left|\mathrm{Z}_{2 \min }\right|=3,818 \Omega$

$\left|Z_{2 \text { mak }}\right|=6,259 \Omega$

$\left|Z_{2 \mathrm{P}}\right|=6,259 \Omega$

Zone 3

$\mathrm{Z}_{3 \mathrm{P}}=1,2\left(\mathrm{ZL}_{11}+\mathrm{ZL}_{31}\right)$

$\mathrm{Z}_{3 \mathrm{~S}}=\mathrm{Z}_{3 \mathrm{P}} \frac{C T p \times V T s}{C T s \times V T p}$

$\mathrm{Z}_{3 \mathrm{~S}}=11,204 \frac{3000 \times 100}{1 \times 150000}$

$\left|\mathrm{Z}_{3 \mathrm{P}}\right|=11,204 \Omega$

$\left|\mathrm{Z}_{3 \mathrm{~S}}\right|=22,408 \Omega$

\section{Hasil dan Analisa}

\subsection{Perbandingan Nilai Jangkauan Rele}

Setelah melakukan perhitungan sesuai dengan persamaan rumus 1-5 maka dapat dilihat perbandingan nilai jangkauan rele yang ditampilkan pada Tabel 3.

Tabel 3. Perbandingan Eksisting dan Resetting

\begin{tabular}{lccc}
\hline Rele & Zona & $\begin{array}{c}\text { Jangkauan Lama } \\
(\%)\end{array}$ & $\begin{array}{c}\text { Jangkauan } \\
\text { Baru (\%) }\end{array}$ \\
\hline \multirow{3}{*}{ Kudus 1 - Jekulo 1 } & Zona 1 & 80.80 & 80.80 \\
& Zona 2 & 204.38 & 195.19 \\
& Zona 3 & 451.22 & 351.88 \\
Kudus 2 - Jekulo 2 & Zona 1 & 80.80 & 80.80 \\
& Zona 2 & 203.75 & 195.19 \\
& Zona 3 & 451.22 & 351.88 \\
Jekulo 1 - Pati 1 & Zona 1 & 80.50 & 80.50 \\
& Zona 2 & 245.27 & 223.24 \\
& Zona 3 & 418.72 & 415.52 \\
Jekulo 2 - Pati 2 & Zona 1 & 80.50 & 80.50 \\
& Zona 2 & 239.53 & 223.24 \\
& Zona 3 & 418.72 & 415.52 \\
Pati 1 - Jekulo 1 & Zona 1 & 80.50 & 80.50 \\
& Zona 2 & 145.28 & 125.21 \\
& Zona 3 & 183.60 & 181.88 \\
Pati 2 - Jekulo 2 & Zona 1 & 80.50 & 80.50 \\
& Zona 2 & 121.04 & 121.04 \\
& Zona 3 & 183.60 & 181.88 \\
& Zona 1 & 86.66 & 86.66 \\
Jekulo 1 - Kudus 1 & Zona 2 & 196.46 & 188.06 \\
& Zona 3 & 620.91 & 396.09 \\
& Zona 1 & 86.66 & 86.66 \\
Jekulo 2 - Kudus 2 & Zona 2 & 196.46 & 188.06 \\
& Zona 3 & 620.91 & 396.09 \\
\hline
\end{tabular}

Pada Tabel 3 dapat dilihat bahwa setelah dilakukan resetting atau perhitungan ulang, nilai jangkuan rele jarak ditiap zona sudah sesuai dengan standar yang ada.

\subsection{Perbandingan Koordinasi Rele Jarak}

Perbandingan koordinasi rele jarak digunakan untuk mengetahui perbedaan koordinasi pada kondisi eksisting dan resetting. 
TRANSIENT, VOL. 7, NO. 1, MARET 2018, ISSN: 2302-9927, 86

\subsubsection{Saluran Kudus 1 - Jekulo 1 - Pati 1}

Untuk melihat koordinasi antar rele jarak dapat dilihat menggunakan fitur Time Distance Coordination (TDC) yang terdapat pada software DIgSILENT 14.1. Perbandingan koordinasi rele jarak saluran Kudus 1 - Pati 1 ditampilkan pada Gambar 3.

(a)

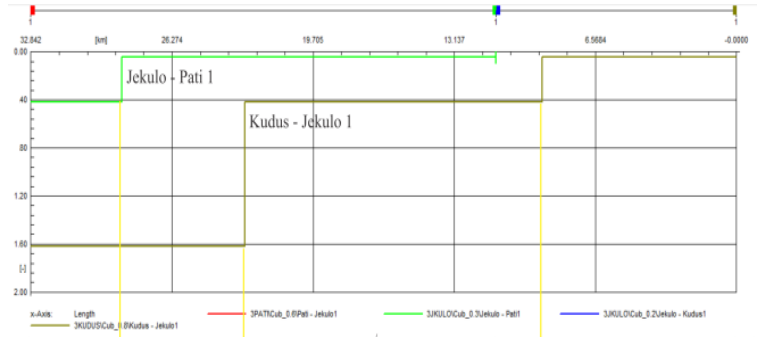

(b)

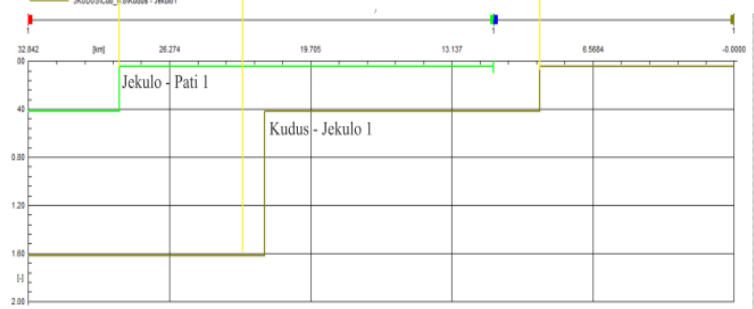

Gambar 3. Perbandingan TDC Kudus 1 - Jekulo 1 - Pati 1 Eksisting (a) dan Resetting (b)

Gambar 3 (a) menunjukkan bahwa koordinasi rele jarak pada kondisi eksisting sudah baik. Hal ini dikarenakan tidak terjadi overlapping antar rele jarak. Namun, pada saat dilihat nilai jangkuannya, beberapa rele jarak memiliki besar jangkauan yang berbeda. Dalam kondisi eksisting (a) dan resetting (b) rele jarak pada zona 1 memiliki nilai jangkauan yang sama. Jangkauan zona 1 pada kondisi eksisting ialah $80,80 \%$ dari total panjang saluran Kudus - Jekulo dan $80,50 \%$ dari total panjang saluran Jekulo - Pati. Dimana pada standar yang ditetapkan oleh IEEE, zona 1 memiliki jangkauan 80\% $90 \%$ dari saluran yang dilindungi. Jangkauan rele jarak zona 1 tidak dilakukan resetting dikarenakan sudah sesuai dengan standar, sehingga nilai jangkauan zona 1 kondisi eksisting dan resetting memiliki jangkauan yang sama.

Untuk jangkauan zona 2 rele jarak pada kondisi eksisting (a) memiliki jangkauan zona 2 yang lebih panjang daripada zona 2 saat kondisi resetting (b). Jangkauan zona 2 pada kondisi eksisting ialah 204\% dari saluran utama yang dilindungi. Menurut standar IEEE dan NPAG nilai jangkauan untuk zona 2 ialah sebesar 120\% hingga 197\% dari saluran yang dilindungi. Setelah dilakukan resetting (b), dapat dilihat bahwa nilai jangkauan zona 2 menjadi lebih pendek dibandingkan dengan kondisi eksisting. Nilai jangkauan zona 2 menjadi $195 \%$ dari total saluran utama yang dilindungi. Dapat dilihat bahwa hasil koordinasi rele jarak pada kondisi setelah resetting menunjukkan nilai jangkauan zona 2 rele jarak subsistem Kudus 1 arah Jekulo 1 telah sesuai dengan standar.

\subsubsection{Saluran Kudus 2 - Jekulo 2 - Pati 2}

Untuk melihat koordinasi antar rele jarak dapat dilihat menggunakan fitur Time Distance Coordination yang terdapat pada software DIgSILENT 14.1. Perbandingan koordinasi rele jarak saluran Kudus 2 - Pati 2 ditampilkan pada Gambar 4.

(a)

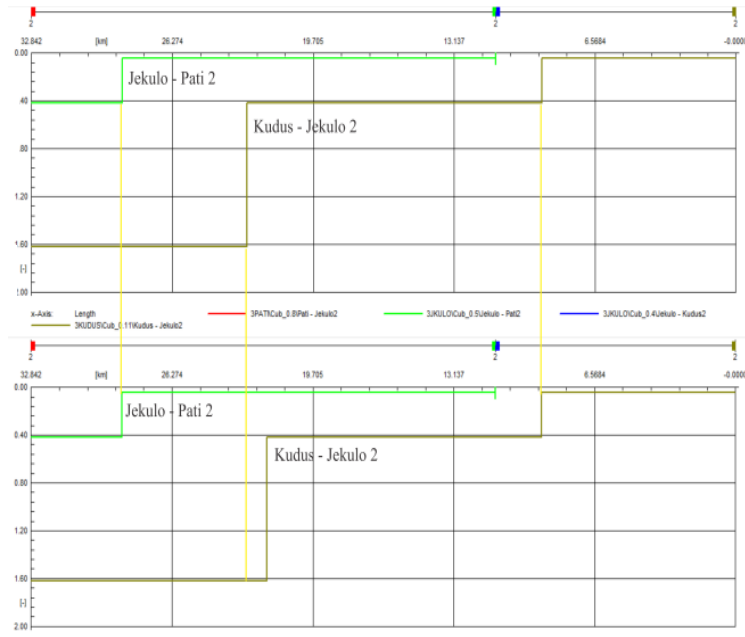

Gambar 4. Perbandingan TDC Kudus 2 - Jekulo 2 - Pati 2 Eksisting (a) dan Resetting (b)

Gambar 4 (a) menunjukkan bahwa koordinasi rele jarak pada kondisi eksisting sudah baik. Hal ini dikarenakan tidak terjadi overlapping antar rele jarak. Namun, pada saat dilihat nilai jangkuannya, beberapa rele jarak memiliki besar jangkauan yang berbeda. Dalam kondisi eksisting (a) dan resetting (b) rele jarak pada zona 1 memiliki nilai jangkauan yang sama. Jangkauan zona 1 pada kondisi eksisting ialah $80,80 \%$ dari total panjang saluran Kudus - Jekulo dan 80,50\% dari total panjang saluran Jekulo - Pati. Dimana pada standar yang ditetapkan oleh IEEE, zona 1 memiliki jangkauan 80\% $90 \%$ dari saluran yang dilindungi. Jangkauan rele jarak zona 1 tidak dilakukan resetting dikarenakan sudah sesuai dengan standar, sehingga nilai jangkauan zona 1 kondisi eksisting dan resetting memiliki jangkauan yang sama.

Untuk jangkauan zona 2 rele jarak pada kondisi eksisting (a) memiliki jangkauan zona 2 yang lebih panjang daripada zona 2 saat kondisi resetting (b). Jangkauan zona 2 pada kondisi eksisting ialah 203\% dari saluran utama yang dilindungi. Menurut standar IEEE dan NPAG nilai jangkauan untuk zona 2 ialah sebesar 120\% hingga 197\% dari saluran yang dilindungi. Setelah dilakukan resetting (b), dapat dilihat bahwa nilai jangkauan zona 2 menjadi lebih pendek dibandingkan dengan kondisi eksisting. Nilai jangkauan zona 2 menjadi $195 \%$ dari total saluran utama yang dilindungi. Dapat dilihat bahwa hasil koordinasi rele jarak pada kondisi setelah resetting menunjukkan nilai jangkauan zona 2 rele jarak subsistem Kudus 2 arah Jekulo 2 telah sesuai dengan standar. 


\subsubsection{Saluran Pati 1 - Jekulo 1 - Kudus 1}

Untuk melihat koordinasi antar rele jarak dapat dilihat menggunakan fitur Time Distance Coordination yang terdapat pada software DIgSILENT 14.1. Perbandingan koordinasi rele jarak saluran Kudus 2 - Pati 2 ditampilkan pada Gambar 5.

(a)

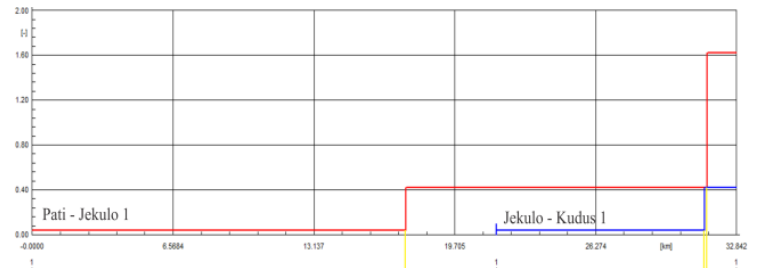

(b)

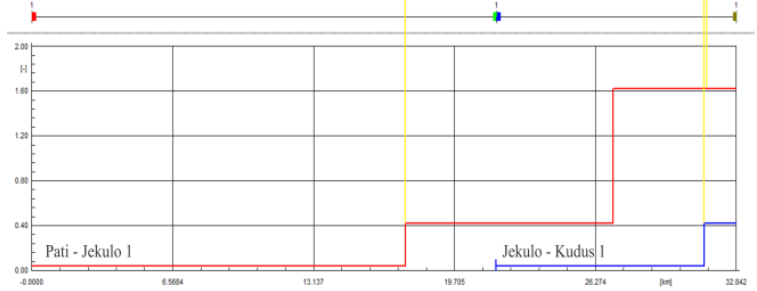

Gambar 5. Perbandingan TDC Pati 1 - Jekulo 1 - Kudus 1 Eksisting (a) dan Resetting (b)

Gambar 5 (a) menunjukkan bahwa koordinasi rele jarak pada kondisi eksisting belum baik. Hal ini dikarenakan adanya overlapping antar rele jarak, walaupun hanya sedikit. Pada saat dilihat nilai jangkuannya, beberapa rele jarak memiliki besar jangkauan yang berbeda. Dalam kondisi eksisting (a) dan resetting (b) rele jarak pada zona 1 memiliki nilai jangkauan yang sama. Jangkauan zona 1 pada kondisi eksisting ialah $80,50 \%$ dari total panjang saluran Pati - Jekulo dan 86,66\% dari total panjang saluran Jekulo - Kudus. Dimana pada standar yang ditetapkan oleh IEEE, zona 1 memiliki jangkauan $80 \%$ $90 \%$ dari saluran yang dilindungi. Jangkauan rele jarak zona 1 tidak dilakukan resetting dikarenakan sudah sesuai dengan standar, sehingga nilai jangkauan zona 1 kondisi eksisting dan resetting memiliki jangkauan yang sama.

Untuk jangkauan zona 2 rele jarak pada kondisi eksisting (a) memiliki jangkauan zona 2 yang lebih panjang dari pada zona 2 saat kondisi resetting (b). Jangkauan zona 2 pada kondisi eksisting ialah $145 \%$ dari saluran utama yang dilindungi. Menurut standar IEEE dan NPAG nilai jangkauan untuk zona 2 ialah sebesar $120 \%$ hingga $125,84 \%$ dari saluran yang dilindungi. Setelah dilakukan resetting (b), dapat dilihat bahwa nilai jangkauan zona 2 menjadi lebih pendek dibandingkan dengan kondisi eksisting. Nilai jangkauan zona 2 menjadi $125,21 \%$ dari total saluran utama yang dilindungi. Dapat dilihat bahwa hasil koordinasi rele jarak pada kondisi setelah resetting menunjukkan nilai jangkauan zona 2 rele jarak subsistem Pati 1 arah Jekulo 1 telah sesuai dengan standar.

\subsubsection{Saluran Pati 2 - Jekulo 2 - Kudus 2}

Untuk melihat koordinasi antar rele jarak dapat dilihat menggunakan fitur Time Distance Coordination yang terdapat pada software DIgSILENT 14.1. Perbandingan koordinasi rele jarak saluran Kudus 2 - Pati 2 ditampilkan pada Gambar 6.

(a)

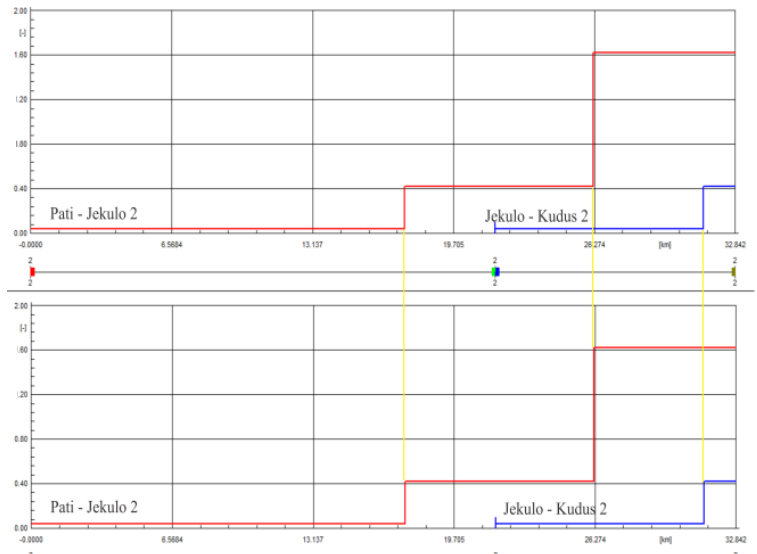

Gambar 6. Perbandingan TDC Pati 2 - Jekulo 2 - Kudus 2 Eksisting (a) dan Resetting (b)

Gambar 6 (a) menunjukkan bahwa koordinasi rele jarak pada kondisi eksisting sudah baik. Hal ini dikarenakan tidak terjadi overlapping antar rele jarak. Namun, pada saat dilihat nilai jangkuannya, rele jarak memiliki besar jangkauan yang sama. Dalam kondisi eksisting (a) dan resetting (b) rele jarak pada zona 1 memiliki nilai jangkauan yang sama. Jangkauan zona 1 pada kondisi eksisting ialah $80,50 \%$ dari total panjang saluran Pati Jekulo dan 86,66\% dari total panjang saluran Jekulo Kudus. Dimana pada standar yang ditetapkan oleh IEEE, zona 1 memiliki jangkauan $80 \%$ - 90\% dari saluran yang dilindungi. Jangkauan rele jarak zona 1 tidak dilakukan resetting dikarenakan sudah sesuai dengan standar, sehingga nilai jangkauan zona 1 kondisi eksisting dan resetting memiliki jangkauan yang sama.

Untuk jangkauan zona 2 rele jarak pada kondisi eksisting (a) memiliki jangkauan zona 2 yang sama dengan kondisi resetting (b). Jangkauan zona 2 pada kondisi eksisting ialah $121 \%$ dari saluran utama yang dilindungi. Menurut standar IEEE dan NPAG nilai jangkauan untuk zona 2 ialah sebesar $120 \%$ hingga $125,84 \%$ dari saluran yang dilindungi. Jangkauan rele jarak zona 2 tidak dilakukan resetting dikarenakan sudah sesuai dengan standar, sehingga nilai jangkauan zona 2 kondisi eksisting dan resetting memiliki jangkauan yang sama. Dapat dilihat bahwa hasil koordinasi rele jarak pada subsistem Pati 2 arah Jekulo 2 telah sesuai dengan standar. 


\subsection{Skenario Gangguan Hubung Singkat}

Skenario gangguan hubung singkat dibuat untuk melihat kinerja dari suatu rele. Skenario gangguan hubung singkat ditunjukkan pada Tabel 4.

Tabel 4. Skenario Gangguan Hubung Singkat

\begin{tabular}{cccc}
\hline Skenario & Letak & Jenis Gangguan & $\begin{array}{c}\text { Letak Simulasi } \\
\text { Gangguan }\end{array}$ \\
\hline \multirow{3}{*}{ Skenario 1 } & Tower 57 & 3 fasa & $98 \%$ \\
& & 2 fasa & $98 \%$ \\
& & 2 fasa ke tanah & $98 \%$ \\
Skenario 2 & Tower 14 & 3 fasa & $98 \%$ \\
& & 2 fasa & $24 \%$ \\
& & 2 fasa ke tanah & $24 \%$ \\
& & 1 fasa ke tanah & $24 \%$ \\
\hline
\end{tabular}

\subsubsection{Skenario 1}

Skenario 1 merupakan gangguan yang terjadi diantara menara SUTT (Saluran Udara Tegangan Tinggi) 57 pada saluran susbsistem Jekulo arah Pati. Hasil dari R-X Diagram kondisi eksisting ditampilkan pada Gambar 7.

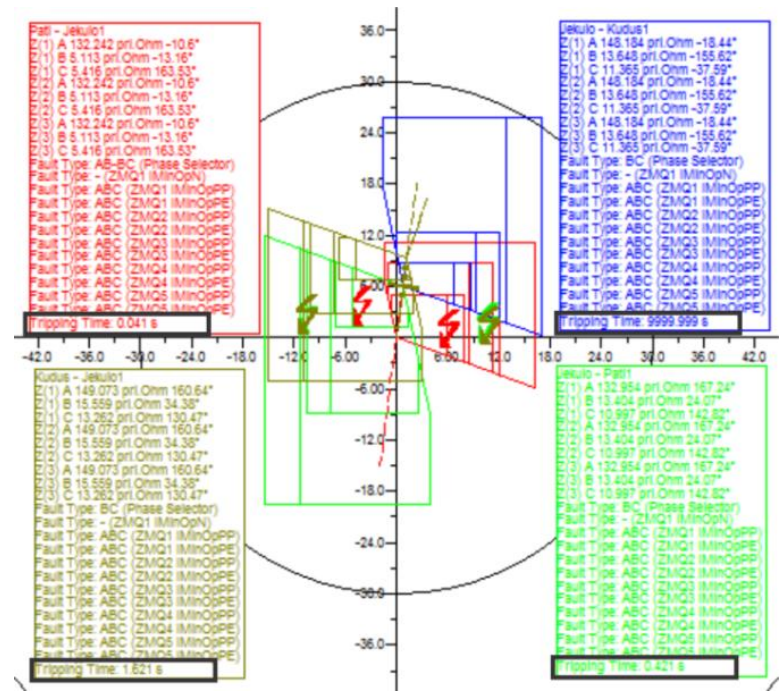

Gambar 7. R-X Diagram Gangguan 2 Fasa Eksisting

Pada Gambar 7 dapat dilihat kinerja rele jarak subsistem Kudus - Pati secara 2 (dua) arah saat terjadi gangguan hubung singkat 2 fasa. Gangguan terletak diantara subsistem Jekulo dan subsistem Pati sejauh 98\%. Waktu kerja rele jarak untuk mengisolir gangguan pada masing masing subsistem ditampilkan sesuai Gambar 7. Dari hasil simulasi yang telah dilakukan semua rele jarak sudah bekerja dengan baik.

Rele jarak pada subsistem Kudus - Jekulo 1 bekerja dengan waktu 1,621 detik. Hal ini dikarenakan zona 3 rele jarak subsistem Kudus - Jekulo 1 membaca gangguan hubung singkat 2 fasa, sedangkan rele jarak pada subsistem Jekulo - Kudus 1 tidak mengalami trip dikarenakan rele jarak pada subsistem tersebut tidak mendeteksi adanya gangguan hubung singkat didepannya. Pada subsistem Pati - Jekulo 1 rele jarak bekerja dengan waktu 0,041 detik. Ini dikarenakan gangguan hubung singkat 2 fasa dibaca oleh zona 1 rele jarak subsistem Pati - Jekulo 1. Sementara pada subsistem Jekulo - Pati 1 kerja rele jarak ialah 0,421 detik. Ini disebabkan zona 2 rele jarak subsistem Jekulo - Pati 1 membaca gangguan hubung singkat 2 fasa. Selanjutnya hasil dari R-X Diagram kondisi resetting ditampilkan pada Gambar 8.

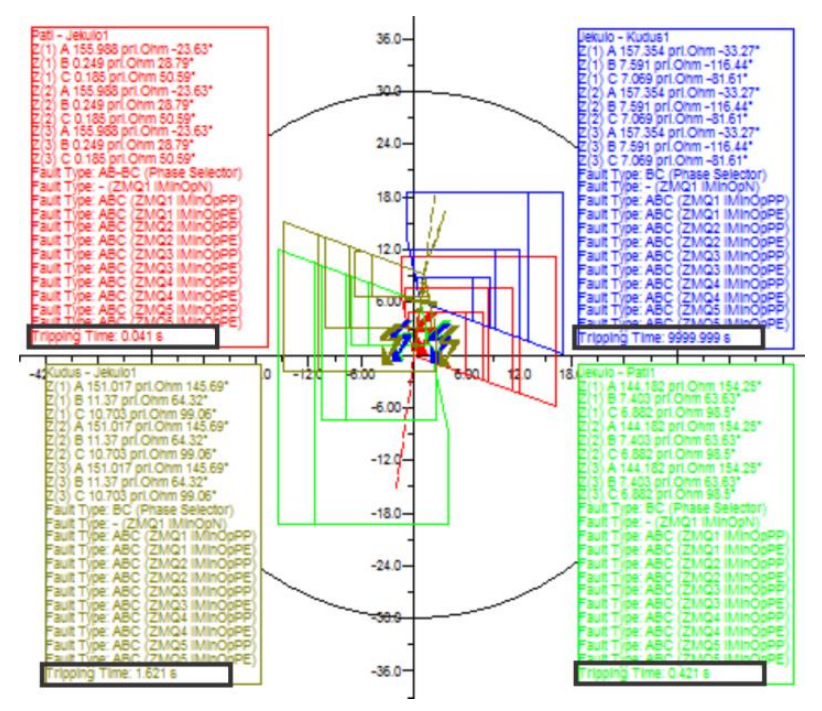

Gambar 8. R-X Diagram Gangguan 2 Fasa Resetting

Pada Gambar 8 dapat dilihat kinerja rele jarak subsistem Kudus - Pati secara 2 (dua) arah saat terjadi gangguan hubung singkat 2 fasa. Gangguan terletak diantara subsistem Jekulo dan subsistem Pati sejauh 98\%. Waktu kerja rele jarak untuk mengisolir gangguan pada masing masing subsistem ditampilkan sesuai Gambar 8. Dari hasil simulasi yang telah dilakukan semua rele jarak sudah bekerja dengan baik.

Rele jarak pada subsistem Kudus - Jekulo 1 bekerja dengan waktu 1,621 detik. Hal ini dikarenakan gangguan hubung singkat 2 fasa dibaca oleh zona 3 rele jarak subsistem Kudus - Jekulo 1, sedangkan rele jarak pada subsistem Jekulo - Pati 1 bekerja dengan waktu 0,421 detik. Ini dikarenakan zona 2 rele jarak subsistem Jekulo - Pati 1 membaca gangguan hubung singkat 2 fasa.

Pada subsistem Pati - Jekulo 1 kerja rele jarak ialah 0,041 detik. Ini disebabkan zona 1 rele jarak subsistem Pati Jekulo 1 membaca gangguan hubung singkat 2 fasa. Sementara pada subsistem Jekulo - Kudus 1 rele jarak tidak mengalami trip dikarenakan rele jarak pada subsistem tersebut tidak mendeteksi adanya gangguan hubung singkat didepannya. Kondisi eksisting dan resetting menunjukkan hasil yang sama. Hal ini membuktikan bahwa ketika terjadi gangguan hubung 
singkat 2 fasa pada lokasi 98\% dari saluran Jekulo arah Pati rele jarak sudah bekerja dengan baik.

Dengan simulasi yang sama dengan jenis gangguan 3 fasa, 2 fasa ke tanah dan 1 fasa ke tanah diperoleh Tabel 5

Tabel 5. Data Kinerja Rele Kondisi Eksisting Skenario 1

\begin{tabular}{cccccc}
\hline \multirow{2}{*}{ Saluran } & $\begin{array}{c}\text { Jenis } \\
\text { Gangguan }\end{array}$ & $\begin{array}{c}\text { Kudus - } \\
\text { Jekulo }\end{array}$ & $\begin{array}{c}\text { Jekulo- } \\
\text { Pati }\end{array}$ & $\begin{array}{c}\text { Pati - } \\
\text { Jekulo }\end{array}$ & $\begin{array}{c}\text { Jekulo- } \\
\text { Kudus }\end{array}$ \\
\hline \multirow{4}{*}{1} & 3 fasa & 1.621 & 0.421 & 0.041 & - \\
& 2 fasa & 1.621 & 0.421 & 0.041 & - \\
& 2 fasa ke tanah & 1.621 & 0.421 & 0.041 & - \\
& 1 fasa ke tanah & - & 0.421 & 0.041 & - \\
& 3 fasa & 1.621 & 0.421 & 0.041 & - \\
& 2 f fasa & 1.621 & 0.421 & 0.041 & - \\
& 2 fasa ke tanah & 1.621 & 0.421 & 0.041 & - \\
& 1 fasa ke tanah & - & 0.421 & 0.041 & - \\
\hline
\end{tabular}

Tabel 6. Data Kinerja Rele Kondisi Resetting Skenario 1

\begin{tabular}{cccccc}
\hline \multirow{2}{*}{ Saluran } & $\begin{array}{c}\text { Jenis } \\
\text { Gangguan }\end{array}$ & $\begin{array}{c}\text { Kudus - } \\
\text { Jekulo }\end{array}$ & $\begin{array}{c}\text { Jekulo } \\
\text { Pati }\end{array}$ & $\begin{array}{c}\text { Pati - } \\
\text { Jekulo }\end{array}$ & $\begin{array}{c}\text { Jekulo- } \\
\text { Kudus }\end{array}$ \\
\hline \multirow{4}{*}{1} & 3 fasa & 1.621 & 0.421 & 0.041 & - \\
& 2 fasa & 1.621 & 0.421 & 0.041 & - \\
& 2 fasa ke tanah & 1.621 & 0.421 & 0.041 & - \\
& 1 fasa ke tanah & - & 0.421 & 0.041 & - \\
2 & 3 fasa & 1.621 & 0.421 & 0.041 & - \\
& 2 fasa & 1.621 & 0.421 & 0.041 & - \\
& 2 fasa ke tanah & 1.621 & 0.421 & 0.041 & - \\
& 1 fasa ke tanah & - & 0.421 & 0.041 & - \\
\hline
\end{tabular}

Berdasarkan Tabel 5 dan Tabel 6 menunjukkan bahwa ketika terjadi gangguan 3 fasa, 2 fasa dan 2 fasa ke tanah semua rele pada subsistem sudah bekerja dengan baik sesuai dengan zona proteksinya. Namun, ketika terjadi gangguan 1 fasa ke tanah rele subsistem Kudus-Jekulo belum bekerja sesuai seharusnya. Hal ini dikarenakan mengalami kondisi under reach.

\subsubsection{Skenario 2}

Skenario 1 merupakan gangguan yang terjadi diantara menara SUTT (Saluran Udara Tegangan Tinggi) 57 pada saluran susbsistem Jekulo arah Pati. Hasil dari R-X Diagram kondisi eksisting ditampilkan pada Gambar 9.

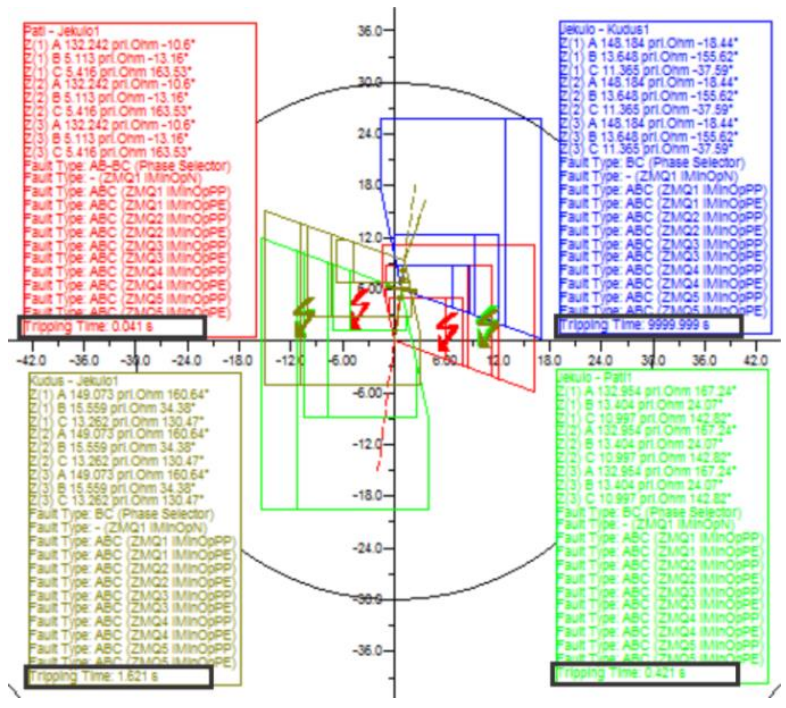

\section{Gambar 9. R-X Diagram Gangguan 2 Fasa Eksisting}

Pada Gambar 9 dapat dilihat kinerja rele jarak subsistem Kudus - Pati secara 2 (dua) arah saat terjadi gangguan hubung singkat 2 fasa. Gangguan terletak diantara subsistem Jekulo dan subsistem Pati sejauh 24\%. Waktu kerja rele jarak untuk mengisolir gangguan pada masing masing subsistem ditampilkan sesuai Gambar 9. Dari hasil simulasi yang telah dilakukan semua rele jarak sudah bekerja dengan baik.

Rele jarak pada subsistem Kudus - Jekulo 1 bekerja dengan waktu 0.421 detik. Hal ini dikarenakan zona 2 rele jarak subsistem Kudus - Jekulo 1 membaca gangguan hubung singkat 2 fasa, sedangkan rele jarak pada subsistem Jekulo - Kudus 1 tidak mengalami trip dikarenakan rele jarak pada subsistem tersebut tidak mendeteksi adanya gangguan hubung singkat didepannya.

Pada subsistem Pati - Jekulo 1 rele jarak bekerja dengan waktu 0,041 detik. Ini dikarenakan gangguan hubung singkat 2 fasa dibaca oleh zona 1 rele jarak subsistem Pati - Jekulo 1. Sementara pada subsistem Jekulo - Pati 1 kerja rele jarak ialah 0,041 detik. Ini disebabkan zona 1 rele jarak subsistem Jekulo - Pati 1 membaca gangguan hubung singkat 2 fasa. Selanjutnya hasil dari R-X Diagram kondisi resetting ditampilkan pada Gambar 10. 


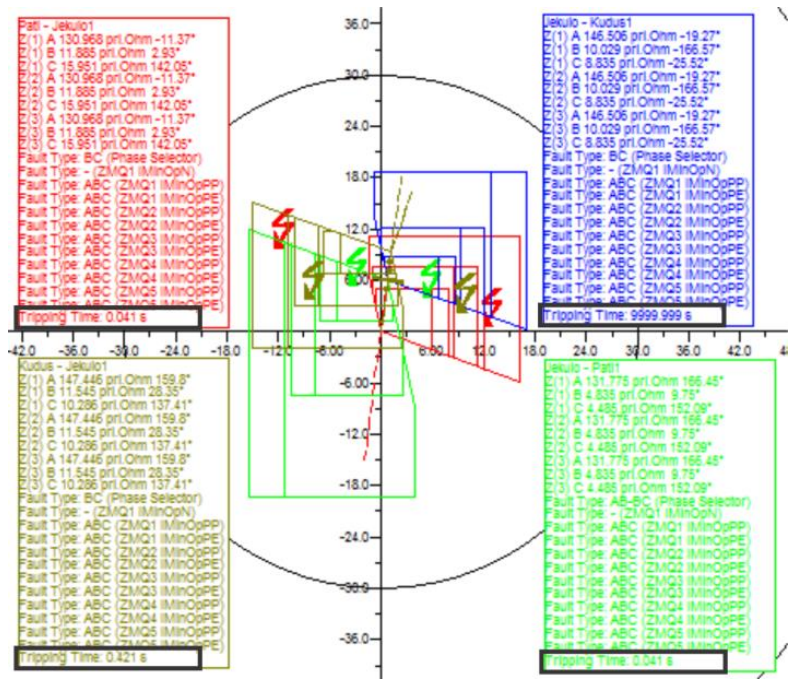

Gambar 10. R-X Diagram Gangguan 2 Fasa Resetting

Pada Gambar 10 dapat dilihat kinerja rele jarak subsistem Kudus - Pati secara 2 (dua) arah saat terjadi gangguan hubung singkat 2 fasa. Gangguan terletak diantara subsistem Jekulo dan subsistem Pati sejauh 24\%. Waktu kerja rele jarak untuk mengisolir gangguan pada masing masing subsistem ditampilkan sesuai Gambar 10. Dari hasil simulasi yang telah dilakukan semua rele jarak sudah bekerja dengan baik.

Rele jarak pada subsistem Kudus - Jekulo 1 bekerja dengan waktu 0,421 detik. Hal ini dikarenakan gangguan hubung singkat 2 fasa dibaca oleh zona 2 rele jarak subsistem Kudus - Jekulo 1, sedangkan kerja rele jarak pada subsistem Jekulo - Pati 1 ialah 0,041 detik. Ini dikarenakan zona 1 rele jarak subsistem Jekulo - Pati 1 membaca gangguan hubung singkat 3 fasa yang terjadi.

Pada subsistem Pati - Jekulo 1 rele jarak bekerja dengan waktu 0,041 detik. Hal ini disebabkan gangguan hubung singkat 2 fasa dibaca oleh zona 1 rele jarak subsistem Pati - Jekulo 1. Sementara, pada subsistem Jekulo - Kudus 1 tidak mengalami trip dikarenakan rele jarak pada subsistem tersebut tidak mendeteksi adanya gangguan hubung singkat didepannya. Kondisi eksisting dan resetting menunjukkan hasil yang sama. Hal ini membuktikan bahwa ketika terjadi gangguan hubung singkat 2 fasa pada lokasi $24 \%$ dari saluran Jekulo arah Pati rele jarak sudah bekerja dengan baik.

Dengan simulasi yang sama dengan jenis gangguan 3 fasa, 2 fasa ke tanah dan 1 fasa ke tanah diperoleh Tabel 7

Berdasarkan Tabel 7 dan Tabel 8 menunjukkan bahwa ketika terjadi gangguan 3 fasa, 2 fasa dan 2 fasa ke tanah semua rele pada subsistem sudah bekerja dengan baik sesuai dengan zona proteksinya. Namun, ketika terjadi gangguan 1 fasa ke tanah rele subsistem Kudus-Jekulo dan subsistem Pati-Jekulo belum bekerja sesuai seharusnya. Hal ini dikarenakan rele mengalami kondisi under reach.

Tabel 7. Data Kinerja Rele Kondisi Eksisting Skenario 2

\begin{tabular}{|c|c|c|c|c|c|}
\hline \multirow[b]{2}{*}{ Saluran } & \multirow[b]{2}{*}{$\begin{array}{c}\text { Jenis } \\
\text { Gangguan }\end{array}$} & \multicolumn{4}{|c|}{ Waktu Trip Kondisi Eksisting } \\
\hline & & $\begin{array}{c}\text { Kudus - } \\
\text { Jekulo }\end{array}$ & $\begin{array}{c}\text { Jekulo - } \\
\text { Pati }\end{array}$ & $\begin{array}{l}\text { Pati - } \\
\text { Jekulo }\end{array}$ & $\begin{array}{c}\text { Jekulo - } \\
\text { Kudus }\end{array}$ \\
\hline \multirow{4}{*}{1} & 3 fasa & 0.421 & 0.041 & 0.041 & - \\
\hline & 2 fasa & 0.421 & 0.041 & 0.041 & - \\
\hline & 2 fasa ke tanah & 0.421 & 0.041 & 0.041 & - \\
\hline & 1 fasa ke tanah & 1.621 & 0.041 & 0.421 & - \\
\hline \multirow{4}{*}{2} & 3 fasa & 0.421 & 0.041 & 0.041 & - \\
\hline & 2 fasa & 0.421 & 0.041 & 0.041 & - \\
\hline & 2 fasa ke tanah & 0.421 & 0.041 & 0.041 & - \\
\hline & 1 fasa ke tanah & 1.621 & 0.041 & 1.621 & - \\
\hline
\end{tabular}

Tabel 8. Data Kinerja Rele Kondisi Resetting Skenario 2

\begin{tabular}{|c|c|c|c|c|c|}
\hline \multirow[b]{2}{*}{ Saluran } & \multirow[b]{2}{*}{$\begin{array}{c}\text { Jenis } \\
\text { Gangguan }\end{array}$} & \multicolumn{4}{|c|}{ Waktu Trip Kondisi Resetting } \\
\hline & & $\begin{array}{c}\text { Kudus - } \\
\text { Jekulo }\end{array}$ & $\begin{array}{c}\text { Jekulo - } \\
\text { Pati }\end{array}$ & $\begin{array}{l}\text { Pati - } \\
\text { Jekulo }\end{array}$ & $\begin{array}{c}\text { Jekulo - } \\
\text { Kudus }\end{array}$ \\
\hline \multirow{4}{*}{1} & 3 fasa & 0.421 & 0.041 & 0.041 & - \\
\hline & 2 fasa & 0.421 & 0.041 & 0.041 & - \\
\hline & 2 fasa ke tanah & 0.421 & 0.041 & 0.041 & - \\
\hline & 1 fasa ke tanah & 1.621 & 0.041 & 1.621 & - \\
\hline \multirow{4}{*}{2} & 3 fasa & 0.421 & 0.041 & 0.041 & - \\
\hline & 2 fasa & 0.421 & 0.041 & 0.041 & - \\
\hline & 2 fasa ke tanah & 0.421 & 0.041 & 0.041 & - \\
\hline & 1 fasa ke tanah & 1.621 & 0.041 & 1.621 & - \\
\hline
\end{tabular}

\section{Kesimpulan}

Berdasarkan hasil simulasi koordinasi dan kinerja rele jarak subsistem Kudus - Pati secara 2 arah yang telah dilakukan menggunakan software DIgSILENT, maka dapat diketahui bahwa pada kondisi eksisting terdapat beberapa rele jarak yang nilai jangkauannya belum sesuai dengan standar IEEE dan NPAG Alstom. Setelah dilakukan perhitungan ulang (resetting), nilai jangkauan semua rele sudah sesuai dengan standar. Koordinasi antara rele yang ada di GI Kudus arah Jekulo dengan rele di depannya yaitu rele pada GI Jekulo arah Pati tidak menglami overlapping pada kondisi eksisting maupun resetting.

Koordinasi antara rele yang ada di GI Pati arah Jekulo dengan rele pada GI Jekulo arah Kudus tidak mengalami overlapping lagi setelah adanya resetting. Rele jarak sudah bekerja sesuai dengan waktu kerjanya pada saat gangguan hubung singkat 3 fasa, 2 fasa, dan 2 fasa ke tanah. Sementara untuk gangguan 1 fasa ke tanah terdapat rele jarak yang belum sesuai waktu kerjanya dikarenakan rele bekerja secara under reach.

Studi lebih lanjut dapat dikembangkan dengan mengkoordinasikan rele jarak sebagai main protection dan Over Current Relay (OCR) sebagai backup protection serta mengevaluasi rele jarak pada subsistem lain di wilayah PT. PLN (Persero) APP Semarang.

\section{Referensi}

[1]. Ir. Sulasno, Analisis Sistem Tenaga Listrik, Kedua ed. Semarang: Badan Penerbit Universitas Diponegoro, 2001. 
TRANSIENT, VOL. 7, NO. 1, MARET 2018, ISSN: 2302-9927, 91

[2]. Akhmad Jamaah, "Evaluasi Setting Rele Jarak Gardu Induk Ungaran Jaringan 150kV Arah Krapyak-2," ORBITH, vol. 10, pp. 82-89, Maret 2014.

[3]. Rhamandita Sudrajat, Siti Saodah, and Waluyo , "Analisis Penalaan Rele Jarak sebagai Proteksi Utama pada Saluran Udara Tegangan Tinggi $150 \mathrm{kV}$ Bandung Selatan - Cigereleng," Reka Elkomika, vol. 2, pp. 36-48, Januari 2014.

[4]. Tanzil Ramadhan Aljufri, Bambang Supradono, and Luqman Assaffat, "Scanning dan Resetting Distance Relay Pada Penghantar 150 kV Kudus Arah Jekulo," Media Elektrika, vol. 4, Desember 2011.
[5]. Tanzil Ramadhan Aljufri, Bambang Supradono, and Luqman Assaffat, "Scanning dan Resetting Distance Relay Pada Penghantar $150 \mathrm{kV}$ Kudus Arah Jekulo," Media Elektrika, vol. 4, Desember 2011.

[6]. Bayu Seno Adi Nugroho, "Analisis Setting dan Koordinasi Rele Jarak Pada GI 150 KV Pandean Lamper Arah Srondol," Transient, vol. 6, Maret 2017.

[7]. IEEE Guide for Protective Relay Applications to Transmission Lines.: IEEE Std C37.113-2015, 2015.

[8]. ALSTOM, Network Protection \& Automation Guide.: Alstom Grid, 2011. 